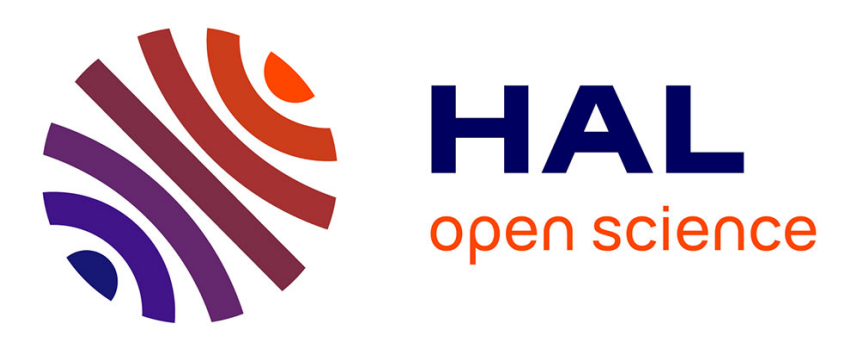

\title{
Factors facilitating and challenging access and adherence to antiretroviral therapy in a township in the Zambian Copperbelt: a qualitative study
}

Elizabeth Grant, Dorothy Logie, Mary Masura, Dermot Gorman, Scott A Murray

\section{To cite this version:}

Elizabeth Grant, Dorothy Logie, Mary Masura, Dermot Gorman, Scott A Murray. Factors facilitating and challenging access and adherence to antiretroviral therapy in a township in the Zambian Copperbelt: a qualitative study. AIDS Care, 2008, 20 (10), pp.1155-1160. 10.1080/09540120701854634. hal-00513445

\section{HAL Id: hal-00513445 \\ https://hal.science/hal-00513445}

Submitted on 1 Sep 2010

HAL is a multi-disciplinary open access archive for the deposit and dissemination of scientific research documents, whether they are published or not. The documents may come from teaching and research institutions in France or abroad, or from public or private research centers.
L'archive ouverte pluridisciplinaire HAL, est destinée au dépôt et à la diffusion de documents scientifiques de niveau recherche, publiés ou non, émanant des établissements d'enseignement et de recherche français ou étrangers, des laboratoires publics ou privés. 



\section{Factors facilitating and challenging access and adherence to antiretroviral therapy in a township in the Zambian Copperbelt: a qualitative study}

\begin{tabular}{|r|l|}
\hline Journal: & $\begin{array}{l}\text { AIDS Care - Psychology, Health \& Medicine - Vulnerable Children } \\
\text { and Youth Studies }\end{array}$ \\
\hline Manuscript ID: & AC-2007-06-0301.R1 \\
\hline Journal Selection: & AIDS Care \\
\hline Keywords: & Adherence, AIDS, Antiretroviral Therapy, HIV, Zambia \\
\hline \multicolumn{2}{|l}{} \\
\hline
\end{tabular}

\section{s ScholarONE \\ Manuscript Central}




\section{Factors facilitating and challenging access and adherence to antiretroviral therapy in a township in the Zambian Copperbelt: a qualitative study_revision}

\section{Abstract}

Antiretroviral therapy is increasingly available in African communities. We set out to gain patient perceptions on factors which facilitate and challenge access and adherence to such therapy. We carried out two semi-structured interviews 12 months apart with 40 HIV positive people drawn from three economically deprived townships in the Copperbelt, Zambia. We also conducted a focus group of 12 of these interviewees. Availability of medication in health facilities did not automatically ensure access to those in need. A prerequisite for commencing on treatment was a positive documented HIV test result, but too few HIV testing centres, fear of family and community rejection, and male domination in sexual and social decision-making prevented a number from coming forward to be tested. Once within the system of care further barriers such as rumours of bad side-effects, inconsistent information, high costs of drugs (at the time of the first interviews), ongoing costs of additional medical tests, overcrowded systems and overworked staff all hindered access to receiving treatment. When taken, therapy brought side effects, the most common being increased appetite and hunger. Yet, despite these barriers and challenges many of those on treatment reported good adherence. Immediate factors such as seeing ill people becoming well; being supported by a friend or family member; and having a watch or clock to keep to a regular regime were important. The increase in the number of people who were expected to die, but were now looking well also shifted community attitudes. HIV/AIDS is beginning to move from a hidden terminal disease, to a chronic condition which is treatable, 


\section{Background}

The adult prevalence of HIV/AIDS in Zambia is $17 \%$, which accounts for much of the drop in life expectancy over the last 30 years from 58 to 37 years (UNAIDS, 2006). Of Zambia's 10.8 million, over one million live with HIV. The Zambian picture is typical of sub-Saharan Africa with more women infected (57\% of the total) and higher infection rates in urban $(23 \%)$ than rural regions (11\%) (Ministry of Health, Zambia, 2005). In 2003 Zambia had approximately 500 patients on ART. Four years later (UNAIDS -WHO, 2005) an estimated 50,000 are receiving treatment through the efforts of the Zambian Government with international support, although four times that number may require antiretroviral therapy (ART).

In June 2005 the Zambian government announced that ART would be made available free of charge. A short-fall in health personnel is significantly limiting the scaling up of ART with Zambia having only 400 doctors (Ministry of Health, 2004). Despite this, concerted efforts have increased the availability of drugs at district and community level. Availability of ART drugs in the community, however may not automatically lead to uptake if social and cultural factors are not understood.

In this paper we seek to examine what factors affect a person's decision to seek testing, and then to start and continue with treatment. The perspectives are from a group of patients living in three economically deprived townships in Ndola (HIV prevalence rate 18\%). Ndola is the provincial capital of the Copperbelt and the second 
largest town in Zambia. After three decades of decline, copper and gold mining is seeing resurgence but unemployment is high and poverty widespread. Subsistence farming, a necessity to supplement income or as its main source, has declined as increasing numbers of workers have become too ill to manage even the modest labour involved.

\section{Methods}

We recruited a broad range of people attending the Isubilo Community Resource Programme, which provides care and support in a community setting for those infected with HIV/AIDS in three crowded townships in Ndola. A qualitative longitudinal approach was chosen to best capture in-depth perspectives of the participants over time and in a flexible and sensitive manner (Mays \& Pope, 1996). In March 2005, a local support worker (MM) who was herself HIV +ve, conducted semi-structured interviews with $40 \mathrm{HIV}+\mathrm{ve}$ patients who volunteered to participate after information on the study was disseminated. Participants were recruited to gain a representative sample of those attending the clinics. The majority of those invited for interview took part: those who declined gave as reasons, sickness and fatigue. We developed and piloted an interview guide focussing on the illness experience, being tested, antiretroviral treatment access, and adherence. Following written consent, interviews were conducted in the local language, Bemba, and recorded manually. Twelve months later, the same support worker conducted further interviews with 25 of the previous participants who were still in the area. A focus group drawn from the first interviewees (women 9, men 3) was held by the support worker, SAM and DL three months prior to the second interviews. This provided participant validation of the results of the first set of interviews and was used to shape data collection during 
the second set of interviews. Interviews were transcribed in English, retaining key meaningful local phrases for illustrative purposes as described in a previous study (Murray et al., 2003). Transcripts and field notes from the focus group and interviews were checked and coded by two experienced researchers and analysed around access and adherence and any emerging themes (Green \& Britten, 1998).

\section{Results}

Participants (26 woman and 14 men) ranged from 22 to 50 years, with an average age of 36 years. Five of the participants were married, five were divorced or separated, five gave their status as single and 25 said they had lost their partner. A positive HIV test was a prerequisite to starting treatment. Thus we report factors which impact on people's decision to attend to test, before discussing factors which directly affect access to and adherence with medication. In 2005 only two centres in Ndola were offering voluntary testing for the public. Participants described long queues, unsympathetic, judgmental or exhausted staff. A year later the number of centres had increased but so had demand.

\section{Drivers and barriers to HIV testing.}

The majority of those interviewed during the first set of interviews in 2005 decided to test because they were sick.

"Coughing every now and then" Participant (Pt) 1. "Vaginal sores were not healing" Pt 2. Only a few chose to have a test because of recognized risk, "I was worried by my mother about the results in case I was HIV +ve because 5 of my family had passed away" Pt 3. 
A blaming community discouraged people from seeking a test. Participants described feeling vulnerable with finger pointing, mocking, and accusations of immoral behaviour from others. The fear of being shunned was common among women and exacerbated by threatening comments from their male partners: "When you finish your test don't come back to this house." Focus Group (FG) 1 “This is where the marriage will end.” FG 3

Participants in the focus group described how men were frequently reluctant to come forward for testing if the suggestion and initiative came from their wives, feeling this would undermine their role. In men's opinion, if a wife wanted to go for testing, she should go alone and not involve them. It was their view that the person who tested positive first in a relationship was the one responsible for bringing the disease into the family. A number described how many men talked about their masculinity in terms of sexual activity, multiple sexual partners being a sign of virility and prowess: "For men not to be adulterous is weak.” FG 6 In one focus group a number of participants shared stories of known HIV+ men having sex to purposively infect others, so that "we die many". FG 2.

In 2005 testing positive for HIV was associated with despair, fear and loss. "It felt that this was it, that life was nearly over." $\mathrm{Pt} 7$. "To me death was on my doorstep, there was no hope for me." Pt 8.

The reaction of family, friends and community affected the decision to seek treatment. Some were openly rejected: "Some of my family members still think I am useless since I am HIV+ve and when it comes to making family decisions I am not consulted. I am ignored" Pt 11 or "They have forsaken me. It is like I am already dead." Pt 12. One woman was forced to leave the family home and live outside in a small hut. Another 
spoke of how her family said: "Then go and prepare three coffins, one for you and two for the children" She continued: " They wanted me to die fast so they did not have to care for me, so I wanted to fight this thing." Pt 4.

\section{Access to Antiretroviral therapy}

During the first interviews in 2005, cost dominated every participant's discussion. Before starting ART, tests were required, and the total costs were equivalent to three months living expenses. During the second set of interviews in 2006 ART drugs were free, though costs for tests still remained a barrier.

During interviews in both 2005 and 2006 participants described erratic drug supply with some on waiting lists for up to six months. With huge clinic queues, minimum time was allotted to each patient. Patients moved from one room for a consultation then to another to pay (in 2005) then collect their tablets. Despite good work by "adherence support workers", patients spoke of the difficulty of finding information about their illness or their drugs, aggravated in 2005 by different drug regimes being used. Switching from one regime to another because of procurement difficulties created confusion.

Participants recorded a variety of beliefs about ART and its impact on sexuality, parenthood, money, and hunger. (box 1) These challenged people's understanding and inhibited some from seeking treatment. A lack of consistent information from churches, community programmes, health services, home care, and schools contributed to the confusion. Little written factual material was available.

\section{Box 1 Beliefs and myths in the community about ART}




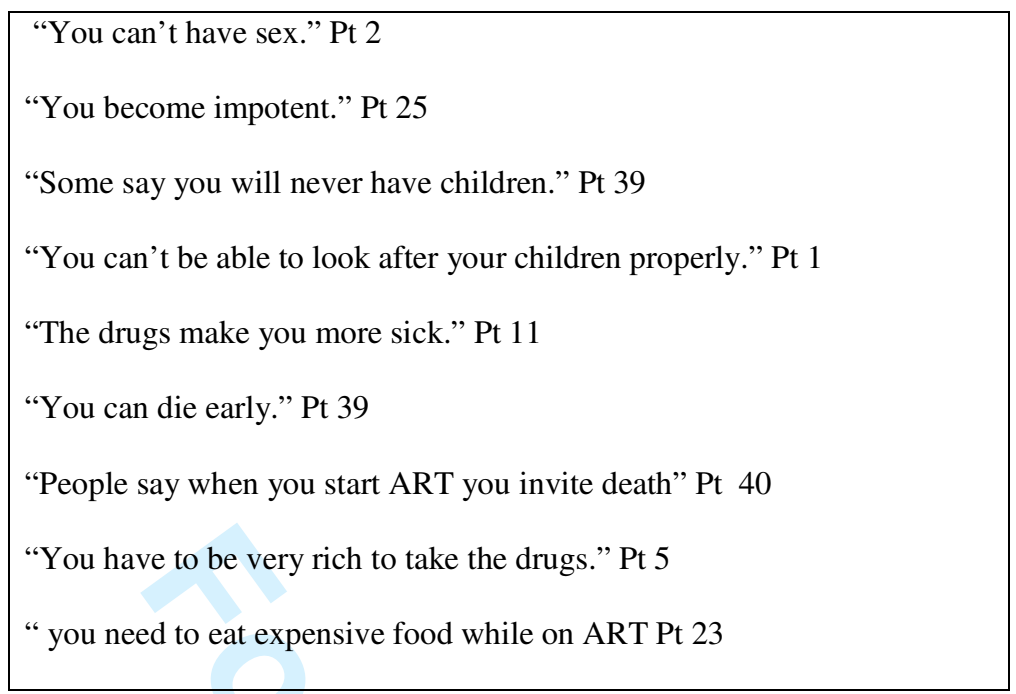

Between 2005 and 2006 community attitudes changed. Though barriers did not disappear, later interviews captured a significant change in attitudes. A potent driver of ART uptake was witnessing physical improvement in those who had been ill. Success stories such as neighbours walking about well again when previously they had been confined to their beds with huge sores and rashes, made previously rejecting families supportive. Some of those not on treatment (because their CD4 counts were above 200) talked of being envious of friends who were on ART for they were actively doing something to improve how they felt. As ART increased in availability, and the number of those looking well again increased, the community became more empathic and accepting and a cycle was created which enabled others to seek testing and treatment. "People are more accepting because they hear on the radio and TV about the illness, lots of people have been tested now." Pt 17. "The illness is common now, it is in the open." Pt 14. "Many people who once were dying are now walking again" (Pt 5)

\section{Compliance with treatment}


The majority of participants claimed good adherence. "It is difficult but I stick to my instructions and I have never missed" Pt 25. One factor was the encouragement from feeling and looking better: "My skin is smooth and I have put on weight" Pt 26. "I don't get sick as I used to" Pt 25. For others it was the ability to positively engage in looking after themselves, "I am confident and happy, it does not matter that I feel sick; I am doing something now that can make me better" Pt 3. Another factor was support from the family encouraging and helping to remind them to take the

Deleted: love and

Deleted: to remember to treatment. Social support, such as someone to help with the tasks of starting to rebuild a life, assistance with cooking, and assistance to grow crops, all encouraged adherence. Drugs brought hope. Participants described how they would now live to see their children finish school rather than leave small orphans.

Taking drugs at regular set times each day aided adherence. Visible reminders such as putting the medication within sight helped. Almost all participants spoke of the value of a clock or watch which acted as the trigger to take their medication. "A watch helps.” Pt 5 “One tablet at 6.00 hours, one tablet 18.00 hours, I have not missed many." Pt 34. Strict regimes created a sense of order and control. There were temptations to stop therapy. "When I had a lot of side effects I nearly stopped" Pt 3. Those with no money described being painfully hungry as ART increased their appetites. A few participants reported they stopped treatment as they could not bear the hunger. "I am not eating enough as I can't afford the food-food is difficult to find" Pt 23. Two men said they had stopped taking drugs because they wished to return to their "previous" life without the hindrance of being tied to burdensome tablet taking, a reminder that they had AIDS.

Deleted: Some 
A theme particularly dominant in the second set of interviews was the need to secure an income. AIDS had destroyed many individual and community livelihoods. Small farms had become barren or wild. Those who adhered well were strengthened by treatment and were re-focussing on their future. This required an active reviving of their livelihood and seeking for income rather than waiting for home based care. People on treatment wanted to stay on treatment so that they could get better. Those getting better wanted employment so that they could "sustain my family needs and to look after my children well” Pt 10. To be "self sustainable”, as one participant said, was the greatest need of everyone who had come through the AIDS crises. It was this type of support that many said would help them achieve long term adherence. What was needed was love, care and money to start a small business, or find work: "Money to pay the rent, get food, and start a business." Pt 6. "I just need money to start business in order to sustain the family" Pt26

\section{Discussion}

Uptake of, and adherence to ART in Zambia is linked not only to its supply but to an array of inter related structural, economic, cultural, and personal factors. Unpicking these and their inter-relationships at local level is vital for effective service development. User-friendly testing and treatment embedded in a health and social system that facilitates adherence, and also offers income rehabilitation, is essential.

Affordable and accessible testing, and encouragement and support to come forward to test by relatives and the community is important. Women are at particular risk from male dominance in relationships, but so too are men who need to redevelop notions of maleness in the Zambian context (Bayliss \& Bujira, 2000). Wives faced criticism 
from their partners if they tried to persuade them to test, and men often would not agree to test if asked by their wives. Combined partner testing is indicated especially for those on ART who are being continually re-exposed to potential infection with another virus strain from a partner who refuses to be tested or use condoms (Jason et al., 2002).

Though globally over 1.6 million people with HIV are receiving treatment, (Horton, 2006) in Sub Saharan Africa this still only represents 5-10\% of those who need it. The short-fall in health systems and health personnel, including laboratory staff and over 1.6 million people in Sub Saharan Africa are receiving treatment, this still only represents about $5-10 \%$ of those who need it (Horton, 2006). diagnostics, and versatile testing centres are still significant limiting factors to scaling up ART (UNAIDS-WHO, 2005). Seeing ill people improving and being able to work again, was the most effective incentive to people seeking testing and treatment for themselves. HIV positive people trained as support workers alongside health staff in both clinics and in the community can help by sharing success, answering questions, and providing practical advice (International HIV/AIDS Alliance, 2005). Integrating HIV care into mainstream health care is essential - especially as seeing physical improvement in others is turning out to be the key to encouraging testing and treatment uptake.

Costs of treatment (in 2005) and the costs of associated tests, transport costs and cost in time were major barriers to starting treatment. Although national guidelines were available in Zambia (National Aids Council, 2004), clarity of charges would greatly facilitate treatment (International HIV/AIDS Alliance, 2003).

Negative community myths and beliefs about ART were barriers to access (Irwin et al., 2003). Their very presence indicates the need to ensure correct, understandable, accessible information about ART and HIV/AIDS. This could be addressed by 
billboards, local radio, newspapers, via faith-based organisations, information sheets, community drama, musicians, and by school education. Radio in Africa can serve as an antidote to the dearth of reliable medical information about how HIV/AIDS is spread, prevented and treated (Sanford Ungar, 2005).

Three major factors facilitated adherence: looking and feeling better, the support of Deleted: Adherence the patients' family, and physical reminders and supports in the form of watches or clocks to take drugs. A recent study with Danish patients on ART found that the most common reason for not adhering was "simply forgetting” (Barford et al., 2006).

Encouraging adherence is the task of the whole community, including the family. One of the greatest concerns about ART roll out in Africa is the fear of poor adherence resulting in drug resistance (Irwin et al., 2003). Our findings present an encouraging picture, confirmed by others, and that factors beyond poverty play an important role (Ferradini et al., 2006; Mills et al., 2006).

As patients on treatment made rapid physical improvement, others were encouraged

Deleted: Ensuring long term adherence to commence and the increasing numbers created a cycle of hope, moving community attitudes about AIDS from being a fearful, unclean disease to a manageable one. A strong message from the voice of those who are HIV+ve is that while drugs have made a huge difference - in patient health and in changing and in creating an accepting community - drugs are not enough. A key message to emerge was that unless the care and support for patients on ART embraces economic, social, and emotional issues, the successes achieved by scale-up programmes may stall. Good adherence needs an economic structure, and for adherence to be maintained patents need to become economically independent. All participants were desperate to find 
work in order to support their families. To achieve viable economic openings will need the co-operation between sectors, churches, business and income generating projects. Crises in adherence may be more likely to be connected to lack of rehabilitation structures than to failure to remember or neglect.

Participants were drawn from three small townships and the numbers interviewed did Deleted: Limitations not permit statistical generalisation. However the qualitative approach allowed people to freely talk about their main concerns to someone from their own community who also had HIV. All who were invited for a second interview agreed. The focus group and second interviews allowed a clarification and a deeper understanding to be gained those who declinajority of those in sickness fatigue.

Deleted: a concerning sensitive issues, such as male attitudes, as well as capturing changes over time in peoples' perceptions. Such longitudinal qualitative research is underutilized in

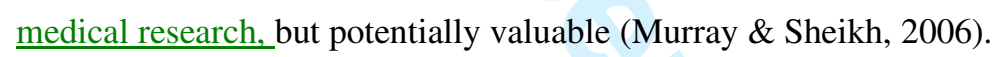

Testing and monitoring must be made easy and take place as near to the patient as Deleted: Policy implications possible. Partners should be encouraged to attend mobile Voluntary Counselling and Treatment (VCT) and ART clinics that use lay treatment support workers (often HIV positive) to offer adherence, prevention advice and defaulter tracing have been successful (McLean \& Dhaliwal, 2005). Understanding culturally specific barriers to adherence will be important in developing evidence-based interventions targeted at the individuals with poor ART adherence (Mills et al., 2006). Treatment systems also needs to be adapted to manage a new cadre of patients - those who expected to die, but who now are getting better. All cadres of workers require training, recognition, and support to ensure sustainability. Rehabilitation (especially economic support) is the fourth stage on the testing, treatment and adherence pathway. 


\section{Conclusions}

Universal access to treatment by 2010 will require greatly scaled up testing and treatment. However for these resources to be utilised, many local factors that challenge uptake and adherence, such as the inequalities between men and women in sexual relationships will need to be addressed. A system which allows easy and socially acceptable access to accurate information, testing, treatment and which marries adherence to supportive economic and social rehabilitation is urgently required. Integrating HIV/AIDS care into the main stream health service is a first step in a long battle. 
Contributions LG, SM and DL designed the study. MM conducted the interviews supported by LG and DG. DL, SM and MM conducted the focus group. All the authors analysed the data, and contributed to writing the paper. LG is the guarantor

\section{Conflict of interest statement}

We declare that we have no conflict of interest.

Approvals Management approval were gained from Isubilo Community Resource Programme Management Team, and ethics approval gained through the executive director of Ndola Hospital 
Barfod, T.S., Sorensen, H.T., Nielsen, H., Rodkjaer, L., \& Obel, N. (2006). 'Simply forgot' is the most frequently stated reason for missed doses of HAART irrespective of degree of adherence. HIV Medicine, 7, 285-90.

Bayliss, C., \& Bujira, J. (2000). AIDS sexuality and gender in Africa: collective strategies and struggles in Tanzania and Zambia. London: Routledge.

Ferradini, L., Jeannin, A., \& Pinoges, L., et al. (2006). Scaling up highly active antiretroviral therapy in a rural district of Malawi: an effectiveness assessment. Lancet, 367, 1335-42.

Government of Zambia Ministry of Health Human Resource Strategic Plan 2005

Green, J., \& Britten, N. (1998). Qualitative research and evidence based medicine. British Medical Journal, 316, 1230-1233.

Horton, R.A. Prescription for AIDS 2006-10. (2006). Lancet, 368, 716-718.

International HIV/AIDS Alliance (2005). Community Education and Referral: Supporting adherence to ARV treatment and prevention for people with HIV in Zambia. www.aidsalliance.org

International HIV/AIDS alliance (2003). Voices from the community. Report of a community consultation on antiretroviral treatment in Zambia November 2002. The International AIDS Alliance. London.

Irwin, A., Millen, J., \& Fallows, D. (2003). Global AIDS: Myths and facts. South End Press, Cambridge M.A.

Jason, T., Blackard, Daniel E., Cohen, \& Kenneth, H. (2002). Mayer Clinical Infectious Diseases, 34, 1108-1114.

McLean, S., \& Dhaliwal, M. (2005). Supporting community action on AIDS in developing Countries Human resources for health exist in Communities International HIV/AIDS Alliance Briefing paper. www.aidalliance.org

Mays, N., \& Pope, C. (1996). Qualitative research in health care. London: British Medical Journal Publishing Group.

Mills, E.J., Nachega, J.B., Buchan, I., Orbinski, J., Attaran, A., \& Singh, S., et al. (2006). Adherence to antiretroviral therapy in sub-Saharan Africa and North America: a meta-analysis. Journal of the American Medical Association, 296, 679-90.

Murray, S.M., Grant, E., Grant, A., \& Kendall, M. (2003). Dying from cancer in developed and developing countries: lessons from two qualitative interview studies of patients and their carers. British Medical Journal, 326, 368.

Murray, S., \& Sheikh, A. (2006). Serial interviews for patients with progressive diseases. Lancet, 368, 901-902.

National AIDS Council (2004). National guidelines on management and Care of Patients with HIV/AIDS. Zambia. 
Report on the Global Aids epidemic UNAIDS 2006 UNAIDS Geneva Switzerland.

Sanford Ungar, Director of the Voice of America (VOA) USAID report http://www.usaid.gov/gn/health/news/010115_radioshow/index.htm

UNAIDS Progress on Global access to HIV antiretroviral therapy: an update on "3 by5". UNAIDS and WHO. Geneva 2005

Zambia HIV/AID Strategic Framework 2006-1010 Ministry of Health, Lusaka, Zambia 
Factors facilitating and challenging access and adherence to antiretroviral therapy in a township in the Zambian

Copperbelt: a qualitative study revision

Dr Elizabeth Grant,

International Health Advisor, NHS Lothian,

Research Fellow, Primary Palliative Care Research Group,

Division of Community Health Sciences: General Practice Section,

University of Edinburgh,

Edinburgh, EH8 9DX.

Dr Dorothy Logie,

International Public Health Consultant,

Cheviot View,

Bowden,

Melrose

TD6 OST

Ms Mary Masura,

Isubilo Community Resource Centre,

Isubilo,

Zambia.

Dr Dermot Gorman

Consultant in Public Health,

NHS Lothian, Deaconess House,

Edinburgh

EH8 9RS

Professor Scott A Murray,

St Columba's Hospice Chair of Primary Palliative Care,

Primary Palliative Care Research Group,

Division of Community Health Sciences: General Practice Section,

University of Edinburgh,

20 West Richmond Street,

Edinburgh

EH8 9DX

Corresponding author: Dr Elizabeth Grant 


\section{Abstract}

Antiretroviral therapy is increasingly available in African communities. We set out to gain patient perceptions on factors which facilitate and challenge access and adherence to such therapy. We carried out two semi-structured interviews 12 months apart with 40 HIV positive people drawn from three economically deprived townships in the Copperbelt, Zambia. We also conducted a focus group of 12 of these interviewees. Availability of medication in health facilities did not automatically ensure access to those in need. A prerequisite for commencing on treatment was a positive documented HIV test result, but too few HIV testing centres, fear of family and community rejection, and male domination in sexual and social decision-making prevented a number from coming forward to be tested. Once within the system of care further barriers such as rumours of bad side-effects inconsistent information, high costs of drugs (at the time of the first interviews), ongoing costs of additional Deleted: negative Deleted: myths Deleted: and medical tests, overcrowded systems and overworked staff all hindered access to receiving treatment. When taken, therapy brought side effects, the most common being increased appetite and hunger. Yet, despite these barriers and challenges many of those on treatment reported good adherence. Immediate factors such as seeing ill people becoming well; being supported by a friend or family member; and having a watch or clock to keep to a regular regime were important. The increase in the number of people who were expected to die, but were now looking well also shifted community attitudes. HIV/AIDS is beginning to move from a hidden terminal disease, to a chronic condition which is treatable,

Deleted: , if not curable 


\section{Background}

The adult prevalence of HIV/AIDS in Zambia is $17 \%$, which accounts for much of the drop in life expectancy over the last 30 years from 58 to 37 years (UNAIDS, 2006). Of Zambia's 10.8 million, over one million live with HIV. The Zambian picture is typical of sub-Saharan Africa with more women infected (57\% of the total) and higher infection rates in urban $(23 \%)$ than rural regions $(11 \%)$ (Ministry of Health, Zambia, 2005). In 2003 Zambia had approximately 500 patients on ART. Four years later (UNAIDS -WHO, 2005) an estimated 50,000 are receiving treatment through the efforts of the Zambian Government with international support, although four times that number may require antiretroviral therapy (ART).

In June 2005 the Zambian government announced that ART would be made available free of charge. A short-fall in health personnel is significantly limiting the scaling up of ART with Zambia having only 400 doctors (Ministry of Health, 2004). Despite this, concerted efforts have increased the availability of drugs at district and community level. Availability of ART drugs in the community, however may not automatically lead to uptake if social and cultural factors are not understood.

In this paper we seek to examine what factors affect a person's decision to seek testing, and then to start and continue with treatment. The perspectives are from a group of patients living in three economically deprived townships in Ndola (HIV prevalence rate 18\%). Ndola is the provincial capital of the Copperbelt and the second largest town in Zambia. After three decades of decline, copper and gold mining is seeing resurgence but unemployment is high and poverty widespread. Subsistence farming, a necessity to supplement income or as its main source, has declined as 
increasing numbers of workers have become too ill to manage even the modest labour involved.

\section{Methods}

We recruited a broad range of people attending the Isubilo Community Resource Programme, which provides care and support in a community setting for those infected with HIV/AIDS in three crowded townships in Ndola. A qualitative longitudinal approach was chosen to best capture in-depth perspectives of the participants over time and in a flexible and sensitive manner (Mays \& Pope, 1996).

In March 2005, a local support worker (MM) who was herself HIV +ve, conducted semi-structured interviews with $40 \mathrm{HIV}+\mathrm{ve}$ patients who volunteered to participate after information on the study was disseminated. Participants were recruited to gain a representative sample of those attending the clinics. The majority of those invited for interview took part: those who declined gave as reasons, sickness and fatigue. We developed and piloted an interview guide focussing on the illness experience, being tested, antiretroviral treatment access, and adherence. Following written consent, interviews were conducted in the local language, Bemba, and recorded manually. Twelve months later, the same support worker conducted further interviews with 25 of the previous participants who were still in the area. A focus group drawn from the first interviewees (women 9, men 3) was held by the support worker, SAM and DL three months prior to the second interviews. This provided participant validation of the results of the first set of interviews and was used to shape data collection during the second set of interviews. Interviews were transcribed in English, retaining key meaningful local phrases for illustrative purposes as described in a previous study (Murray et al., 2003). Transcripts and field notes from the focus group and interviews 
were checked and coded by two experienced researchers and analysed around access and adherence and any emerging themes (Green \& Britten, 1998).

\section{Results}

Participants (26 woman and 14 men) ranged from 22 to 50 years, with an average age of 36 years. Five of the participants were married, five were divorced or separated, five gave their status as single and 25 said they had lost their partner.

A positive HIV test was a prerequisite to starting treatment. Thus we report factors which impact on people's decision to attend to test, before discussing factors which directly affect access to and adherence with medication. In 2005 only two centres in Ndola were offering voluntary testing for the public. Participants described long queues, unsympathetic, judgmental or exhausted staff. A year later the number of centres had increased but so had demand.

\section{Drivers and barriers to HIV testing.}

The majority of those interviewed during the first set of interviews in 2005 decided to test because they were sick.

"Coughing every now and then" Participant (Pt) 1. "Vaginal sores were not healing" Pt 2. Only a few chose to have a test because of recognized risk, "I was worried by my mother about the results in case I was HIV +ve because 5 of my family had passed away" Pt 3 .

A blaming community discouraged people from seeking a test. Participants described feeling vulnerable with finger pointing, mocking, and accusations of immoral behaviour from others. The fear of being shunned was common among women and exacerbated by threatening comments from their male partners: "When you finish 
your test don't come back to this house." Focus Group (FG) 1 “This is where the marriage will end.” FG 3

Participants in the focus group described how men were frequently reluctant to come forward for testing if the suggestion and initiative came from their wives, feeling this would undermine their role. In men's opinion, if a wife wanted to go for testing, she should go alone and not involve them. It was their view that the person who tested positive first in a relationship was the one responsible for bringing the disease into the family. A number described how many men talked about their masculinity in terms of sexual activity, multiple sexual partners being a sign of virility and prowess: "For men not to be adulterous is weak." FG 6 In one focus group a number of participants Deleted: $\mathrm{P}$ shared stories of known HIV+ men having sex to purposively infect others, so that "we die many". FG 2.

In 2005 testing positive for HIV was associated with despair, fear and loss. "It felt that this was it, that life was nearly over." $\mathrm{Pt} 7$. "To me death was on my doorstep, there was no hope for me." Pt 8.

The reaction of family, friends and community affected the decision to seek treatment. Some were openly rejected: "Some of my family members still think I am useless since I am HIV+ve and when it comes to making family decisions I am not consulted. I am ignored” Pt 11 or "They have forsaken me. It is like I am already dead.” Pt 12. One woman was forced to leave the family home and live outside in a small hut. Another spoke of how her family said: "Then go and prepare three coffins, one for you and two for the children" She continued: " They wanted me to die fast so they did not have to care for me, so I wanted to fight this thing." Pt 4. 


\section{Access to Antiretroviral therapy}

During the first interviews in 2005, cost dominated every participant's discussion.

Before starting ART, tests were required, and the total costs were equivalent to three months living expenses. During the second set of interviews in 2006 ART drugs were free, though costs for tests still remained a barrier.

During interviews in both 2005 and 2006 participants described erratic drug supply with some on waiting lists for up to six months. With huge clinic queues, minimum time was allotted to each patient. Patients moved from one room for a consultation then to another to pay (in 2005) then collect their tablets. Despite good work by "adherence support workers", patients spoke of the difficulty of finding information about their illness or their drugs, aggravated in 2005 by different drug regimes being used. Switching from one regime to another because of procurement difficulties created confusion.

Participants recorded a variety of beliefs about ART and its impact on sexuality, parenthood, money, and hunger. (box 1) These challenged people's understanding and inhibited some from seeking treatment. A lack of consistent information from churches, community programmes, health services, home care, and schools contributed to the confusion. Little written factual material was available.

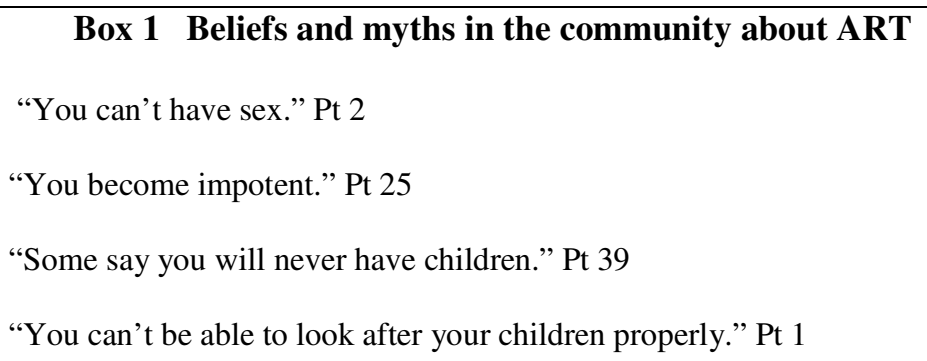




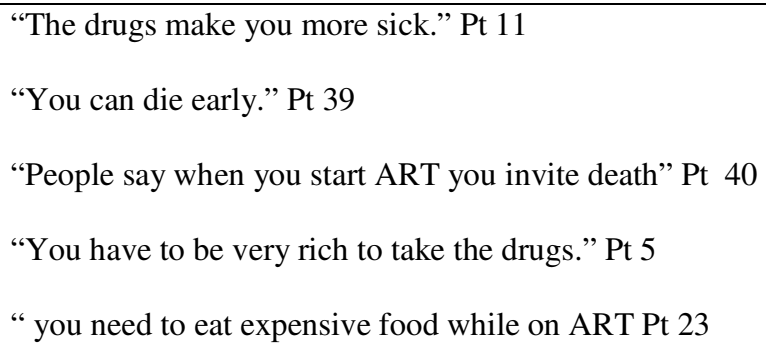

Between 2005 and 2006 community attitudes changed. Though barriers did not disappear, later interviews captured a significant change in attitudes. A potent driver of ART uptake was witnessing physical improvement in those who had been ill. Success stories such as neighbours walking about well again when previously they had been confined to their beds with huge sores and rashes, made previously rejecting families supportive. Some of those not on treatment (because their CD4 counts were above 200) talked of being envious of friends who were on ART for they were actively doing something to improve how they felt. As ART increased in availability, and the number of those looking well again increased, the community became more empathic and accepting and a cycle was created which enabled others to seek testing and treatment. "People are more accepting because they hear on the radio and TV about the illness, lots of people have been tested now." Pt 17. "The illness is common now, it is in the open." Pt 14. "Many people who once were dying are now walking again" (Pt 5)

\section{Compliance with treatment}

The majority of participants claimed good adherence. "It is difficult but I stick to my instructions and I have never missed" Pt 25. One factor was the encouragement from feeling and looking better: "My skin is smooth and I have put on weight" Pt 26. "I don't get sick as I used to" Pt 25. For others it was the ability to positively engage in 
looking after themselves, "I am confident and happy, it does not matter that I feel sick; I am doing something now that can make me better" Pt 3. Another factor was support from the family encouraging and helping to remind them to take the

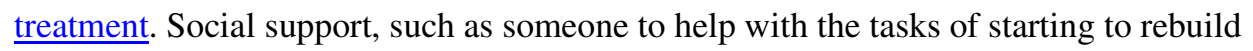
a life, assistance with cooking, and assistance to grow crops, all encouraged adherence. Drugs brought hope. Participants described how they would now live to see their children finish school rather than leave small orphans.

Taking drugs at regular set times each day aided adherence. Visible reminders such as putting the medication within sight helped. Almost all participants spoke of the value of a clock or watch which acted as the trigger to take their medication. "A watch helps.” Pt 5 “One tablet at 6.00 hours, one tablet 18.00 hours, I have not missed many." Pt 34. Strict regimes created a sense of order and control. There were temptations to stop therapy. "When I had a lot of side effects I nearly stopped" Pt 3. Those with no money described being painfully hungry as ART increased their appetites. A few participants reported they stopped treatment as they could not bear the hunger. "I am not eating enough as I can't afford the food-food is difficult to find" Pt 23. Two men said they had stopped taking drugs because they wished to return to their "previous" life without the hindrance of being tied to burdensome tablet taking, a reminder that they had AIDS.

Deleted: Some A theme particularly dominant in the second set of interviews was the need to secure an income. AIDS had destroyed many individual and community livelihoods. Small farms had become barren or wild. Those who adhered well were strengthened by treatment and were re-focussing on their future. This required an active reviving of 
their livelihood and seeking for income rather than waiting for home based care. People on treatment wanted to stay on treatment so that they could get better. Those getting better wanted employment so that they could "sustain my family needs and to look after my children well” Pt 10. To be "self sustainable”, as one participant said, was the greatest need of everyone who had come through the AIDS crises. It was this type of support that many said would help them achieve long term adherence. What was needed was love, care and money to start a small business, or find work: "Money to pay the rent, get food, and start a business." Pt 6. "I just need money to start business in order to sustain the family" Pt26

\section{Discussion}

Uptake of, and adherence to ART in Zambia is linked not only to its supply but to an array of inter related structural, economic, cultural, and personal factors. Unpicking these and their inter-relationships at local level is vital for effective service development. User-friendly testing and treatment embedded in a health and social system that facilitates adherence, and also offers income rehabilitation, is essential.

Affordable and accessible testing, and encouragement and support to come forward to Deleted: HIV testing test by relatives and the community is important. Women are at particular risk from male dominance in relationships, but so too are men who need to redevelop notions of maleness in the Zambian context (Bayliss \& Bujira, 2000). Wives faced criticism from their partners if they tried to persuade them to test, and men often would not agree to test if asked by their wives. Combined partner testing is indicated especially for those on ART who are being continually re-exposed to potential infection with 
another virus strain from a partner who refuses to be tested or use condoms (Jason et al., 2002).

Though globally over 1.6 million people with HIV are receiving treatment, (Horton, 2006) in Sub Saharan Africa this still only represents 5-10\% of those who need it. The short-fall in health systems and health personnel, including laboratory staff and Deleted: Accessing treatment Thoug over 1.6 million people in Sub Saharan Africa are receiving treatment, this still who need it (Horton, 2006). diagnostics, and versatile testing centres are still significant limiting factors to scaling up ART (UNAIDS-WHO, 2005). Seeing ill people improving and being able to work again, was the most effective incentive to people seeking testing and treatment for themselves. HIV positive people trained as support workers alongside health staff in both clinics and in the community can help by sharing success, answering questions, and providing practical advice (International HIV/AIDS Alliance, 2005). Integrating HIV care into mainstream health care is essential - especially as seeing physical improvement in others is turning out to be the key to encouraging testing and treatment uptake.

Costs of treatment (in 2005) and the costs of associated tests, transport costs and cost in time were major barriers to starting treatment. Although national guidelines were available in Zambia (National Aids Council, 2004), clarity of charges would greatly facilitate treatment (International HIV/AIDS Alliance, 2003).

Negative community myths and beliefs about ART were barriers to access (Irwin et al., 2003). Their very presence indicates the need to ensure correct, understandable, accessible information about ART and HIV/AIDS. This could be addressed by billboards, local radio, newspapers, via faith-based organisations, information sheets, community drama, musicians, and by school education. Radio in Africa can serve as 
an antidote to the dearth of reliable medical information about how HIV/AIDS is spread, prevented and treated (Sanford Ungar, 2005).

Three major factors facilitated adherence: looking and feeling better, the support of Deleted: Adherence the patients' family, and physical reminders and supports in the form of watches or clocks to take drugs. A recent study with Danish patients on ART found that the most common reason for not adhering was "simply forgetting” (Barford et al., 2006).

Encouraging adherence is the task of the whole community, including the family. One of the greatest concerns about ART roll out in Africa is the fear of poor adherence resulting in drug resistance (Irwin et al., 2003). Our findings present an encouraging picture, confirmed by others, and that factors beyond poverty play an important role (Ferradini et al., 2006; Mills et al., 2006).

As patients on treatment made rapid physical improvement, others were encouraged Deleted: Ensuring long term adherence to commence and the increasing numbers created a cycle of hope, moving community attitudes about AIDS from being a fearful, unclean disease to a manageable one. A strong message from the voice of those who are HIV+ve is that while drugs have made a huge difference - in patient health and in changing and in creating an accepting community - drugs are not enough. A key message to emerge was that unless the care and support for patients on ART embraces economic, social, and emotional issues, the successes achieved by scale-up programmes may stall. Good adherence needs an economic structure, and for adherence to be maintained patents need to become economically independent. All participants were desperate to find work in order to support their families. To achieve viable economic openings will need the co-operation between sectors, churches, business and income generating 
projects. Crises in adherence may be more likely to be connected to lack of rehabilitation structures than to failure to remember or neglect.

Participants were drawn from three small townships and the numbers interviewed did Deleted: Limitation not permit statistical generalisation. However the qualitative approach allowed people to freely talk about their main concerns to someone from their own community who also had HIV. All who were invited for a second interview agreed. The focus group and second interviews allowed a clarification and a deeper understanding to be gained Deleted: . The majority of those invited those who declined gave as reasons, sickness fatigue.

Deleted: a concerning sensitive issues, such as male attitudes, as well as capturing changes over time in peoples' perceptions. Such longitudinal qualitative research is underutilized $\underline{\text { in }}$ medical research, but potentially valuable (Murray \& Sheikh, 2006).

Testing and monitoring must be made easy and take place as near to the patient as Deleted: Policy implications possible. Partners should be encouraged to attend mobile Voluntary Counselling and Treatment (VCT) and ART clinics that use lay treatment support workers (often HIV positive) to offer adherence, prevention advice and defaulter tracing have been successful (McLean \& Dhaliwal, 2005). Understanding culturally specific barriers to adherence will be important in developing evidence-based interventions targeted at the individuals with poor ART adherence (Mills et al., 2006). Treatment systems also needs to be adapted to manage a new cadre of patients - those who expected to die, but who now are getting better. All cadres of workers require training, recognition, and support to ensure sustainability. Rehabilitation (especially economic support) is the fourth stage on the testing, treatment and adherence pathway.

\section{Conclusions}


Universal access to treatment by 2010 will require greatly scaled up testing and treatment. However for these resources to be utilised, many local factors that challenge uptake and adherence, such as the inequalities between men and women in sexual relationships will need to be addressed. A system which allows easy and socially acceptable access to accurate information, testing, treatment and which marries adherence to supportive economic and social rehabilitation is urgently required. Integrating HIV/AIDS care into the main stream health service is a first step in a long battle. 
Contributions LG, SM and DL designed the study. MM conducted the interviews supported by LG and DG. DL, SM and MM conducted the focus group. All the authors analysed the data, and contributed to writing the paper. LG is the guarantor

\section{Conflict of interest statement}

We declare that we have no conflict of interest.

Approvals Management approval were gained from Isubilo Community Resource Programme Management Team, and ethics approval gained through the executive director of Ndola Hospital

\section{Acknowledgments}

The Winston Churchill Travelling fellowship and the Perry Fund funded this study. We are grateful for the support of the Isubilo Community Resource Programme, Dr Andy Patching, Dr Jabbin Mulwanda and the study participants. We thank Nic Robertson for developing the participant grid, Morag Edwards for secretarial support, and Gordon Scott, Aziz Sheikh, Barbara McPake, and Janet Sikasote for their pertinent comments on this paper.

1.

Formatted: English U.S. 
Barfod, T.S., Sorensen, H.T., Nielsen, H., Rodkjaer, L., \& Obel, N. (2006). 'Simply forgot' is the most frequently stated reason for missed doses of HAART irrespective of degree of adherence. HIV Medicine, 7, 285-90.

Bayliss, C., \& Bujira, J. (2000). AIDS sexuality and gender in Africa: collective strategies and struggles in Tanzania and Zambia. London: Routledge.

Ferradini, L., Jeannin, A., \& Pinoges, L., et al. (2006). Scaling up highly active antiretroviral therapy in a rural district of Malawi: an effectiveness assessment. Lancet, 367, 1335-42.

Government of Zambia Ministry of Health Human Resource Strategic Plan 2005

Green, J., \& Britten, N. (1998). Qualitative research and evidence based medicine. British Medical Journal, 316, 1230-1233.

Horton, R.A. Prescription for AIDS 2006-10. (2006). Lancet, 368, 716-718.

International HIV/AIDS Alliance (2005). Community Education and Referral: Supporting adherence to ARV treatment and prevention for people with HIV in Zambia. www.aidsalliance.org

International HIV/AIDS alliance (2003). Voices from the community. Report of a community consultation on antiretroviral treatment in Zambia November 2002. The International AIDS Alliance. London.

Irwin, A., Millen, J., \& Fallows, D. (2003). Global AIDS: Myths and facts. South End Press, Cambridge M.A.

Jason, T., Blackard, Daniel E., Cohen, \& Kenneth, H. (2002). Mayer Clinical Infectious Diseases, 34, 1108-1114.

McLean, S., \& Dhaliwal, M. (2005). Supporting community action on AIDS in developing Countries Human resources for health exist in Communities International HIV/AIDS Alliance Briefing paper. www.aidalliance.org

Mays, N., \& Pope, C. (1996). Qualitative research in health care. London: British Medical Journal Publishing Group.

Mills, E.J., Nachega, J.B., Buchan, I., Orbinski, J., Attaran, A., \& Singh, S., et al. (2006). Adherence to antiretroviral therapy in sub-Saharan Africa and North America: a meta-analysis. Journal of the American Medical Association, 296, 679-90.

Murray, S.M., Grant, E., Grant, A., \& Kendall, M. (2003). Dying from cancer in developed and developing countries: lessons from two qualitative interview studies of patients and their carers. British Medical Journal, 326, 368.

Murray, S., \& Sheikh, A. (2006). Serial interviews for patients with progressive diseases. Lancet, 368, 901-902.

National AIDS Council (2004). National guidelines on management and Care of Patients with HIV/AIDS. Zambia. 
Report on the Global Aids epidemic UNAIDS 2006 UNAIDS Geneva Switzerland.

Sanford Ungar, Director of the Voice of America (VOA) USAID report http://www.usaid.gov/gn/health/news/010115_radioshow/index.htm

UNAIDS Progress on Global access to HIV antiretroviral therapy: an update on "3 by5". UNAIDS and WHO. Geneva 2005

Zambia HIV/AID Strategic Framework 2006-1010 Ministry of Health, Lusaka, Zambia 